and sound science to resource managers, policymakers and politicians is crucial for managing environmental resources and for reinforcing political decisions. Scientists need more training and mentoring in such skills - and in dealing with unwelcome fallout from lobbyists and the public.

David Lindenmayer Australian National University, Canberra, Australia.

david.lindenmayer@anu.edu.au

\section{Cities: factor in their biological impact}

Richard Forman and Jianguo Wu identify several zones around the world that might be suitable for future urbanization (Nature 537, 608-611; 2016). We suggest that the problem of supporting a growing population needs to be considered from a biological as well as an urban-planning perspective: 'suitable' is not necessarily synonymous with 'biologically sustainable'.

The authors propose that urbanization should avoid biodiversity hotspots - regions that are rich in endemic species and undergoing rapid habitat loss. But this would exclude highly biodiverse yet wellconserved areas, which also need environmental protection.

Forman and Wu also call for global-scale planning. Until that is properly coordinated, governments should not view natural ecosystems as offering potential accommodation for the next billion people. Instead, they need to maximize landuse potential while minimizing its biological impact - for example, by improving cities and the surrounding lands that feed them, and by promoting biodiversity research and protection in conserved areas.

We probably do not need more "suitable" land: we need to make sustainable and efficient use of the land we already live on. Alexandre Antonelli University of Gothenburg and Gothenburg Botanical Garden, Sweden.

Allison Perrigo Forest Cat Editing, Uppsala, Sweden. alexandre.antonelli@bioenv.gu.se

\section{Cities: new fringes to act as safety nets}

Richard Forman and Jianguo Wu suggest that sustainable city expansion should be restricted to selected urban peripheries (Nature 537, 608-611; 2016). Our investigations across five Indian cities indicate that proper planning of such peri-urban areas is crucial.

We define peri-urban areas as a 5-kilometre fringe of development beyond a city's jurisdiction. The India Research Initiative for Peri-Urban

Human-Animal-Environment Interface (see http://perimilk. phfi.org), funded by Canada's International Development Research Centre, is examining the effects of expansion around Bangalore, Ludhiana, Guwahati, Bhubaneshwar and Udaipur on city dwellers. The populations and calculated decadal growth rates of these cities vary from 8.44 million and $49 \%$ (Bangalore) to 0.45 million and $14 \%$ (Udaipur).

Our findings indicate that poor farming practices across all of these peri-urban areas could put food safety at risk, promote the spread of tuberculosis and other zoonotic infections, and accelerate microbial resistance through antibiotic overuse in livestock (our unpublished results). Public health is further threatened by minimal access to proper health care and by inadequate wastemanagement systems.

Without strict oversight, sound planning and investment in building infrastructure, periurban belts stand to aggravate many of the adverse effects of rapid urban growth.

Pranab Chatterjee, Manish Kakkar Public Health Foundation of India, Gurgaon, India.

Tamoghna Biswas Kolkata Medical College, Kolkata, India. manish.kakkar@phfi.org

\section{Trump: voters show importance of SDGs}

Many of the factors that contributed to Donald

Trump's win in the 2016 US presidential election are those that make achievement of the
United Nations' Sustainable Development Goals (SDGs) so pressing. Drawn up to end poverty (goal 1) and inequality (goal 10) and to ensure prosperity, among other aims, the tenet of the SDGs is to 'leave no one behind'.

In the United States, rising inequality and increasing poverty have created a groundswell of the disenfranchised and the dispossessed. Health care (goal 3) and tertiary education (goal 4) are unaffordable for many. Decent work (goal 8) and industry (goal 9) are under threat from automation and globalization, leading to job losses, fuelling racism and driving up crime (counter to goal 11). Extreme weather events related to climate change are on the rise.

All of this has created a potent cocktail of discontent that has manifested in anger towards the establishment. Yet I fear for most, if not all, of the SDGs under a Trump presidency. For example, he has vowed to undermine action against climate change (goal 13) and could jeopardize the development of clean energy (goal 7). He could put biodiversity at risk by making cuts to the Environmental Protection Agency (goals 14 and 15), and he seems to dismiss gender equality (goal 5).

David Griggs Monash University, Clayton, Australia. dave.griggs@monash.edu

\section{Trump: offset fracking risks}

Unconventional gas extraction ('fracking') is likely to be central to the energy policy of presidentelect Donald Trump. I urge the US Congress to tighten current regulations and strike a balance between energy independence and the safeguarding of public health and the environment (see also J. C. S. Long Nature 539, 495; 2016).

The shale-gas revolution has given the United States a security blanket for energy, at a cost to the environment and to health (see M. L. Finkel and J. Hays J. Epidemiol. Community Health 70, 221-222; 2016). Several European countries and US states (including New York, Maryland and parts of California, Colorado and Texas) have therefore issued a moratorium on fracking.

This means that the US energypolicy debate needs a strong public-health and environmental presence. Before drilling starts, it is crucial to collect baseline data to track any related increase in morbidity and mortality. During the extraction process, environmental monitoring will be needed to assess air pollution and its impact; and details of all chemicals used in the process must be disclosed. Flowback fluids should be properly disposed of to protect surface and groundwater. These safeguards will help to counter potential harm to human health and the environment.

Madelon Finkel Weill Cornell Medical College, New York, USA. mfinkel404@aol.com

\section{Trump: polls right, models wrong}

Contrary to popular opinion, the polls were not wrong in last month's US presidential election (see also Nature 539, 339; 2016). The most recent polls in each state predicted the outcome for individual states - but only when the $95 \%$ confidence interval lay outside the polling error. For those predictions with confidence intervals within the polling error, the results were uncertain.

Many pollsters used predictive models to estimate probabilities. Permutations and models are reliable, however, only when projections capture the uncertainty of both the underlying data and the model itself. We cannot claim to make highly certain predictions from highly uncertain data. In this case, some models claimed a certainty of $99 \%$ even though $31 \%$ of the electoralcollege vote was too close to call.

We need to improve the way we explain uncertainty: uncertain data are not wrong, only uncertain. And we must become better consumers of models.

The polls were right. The models were wrong. In this era of big data, we need to emphasize the distinction.

Brandon Steelman Clear Gene, Moss Beach, California, USA. steelman@cleargenes.com 